\title{
Garden visiting as a meaningful occupation for people in later life
}

Rosemary Leaver ${ }^{1}$ and Tania Wiseman ${ }^{2}$

\section{Abstract}

Introduction: Garden visiting, as described in this study, involves visiting private gardens which householders have temporarily opened to the public, in support of charity. In the United Kingdom, garden visiting is a popular occupation which attracts 750,000 people each year. The connections between active gardening and wellbeing are well established, particularly for people in later life. This research explores visiting other people's gardens for leisure in order to deepen our understanding of how garden visiting is experienced as an occupation.

Method: Seven people aged between 60 and 81 years old who considered themselves fully retired were interviewed whilst walking through parks and public gardens. Thematic analysis with inductive coding was used to analyse the data.

Findings: Four themes emerged: time and wellbeing, embodied wellbeing, being part of a gardening community and pondering the creator.

Conclusion: Garden visiting is a complex occupation which brings far-reaching benefits to individuals and communities. Garden visiting also has important implications for increasing wellbeing by grounding people in the present and promoting sensory engagement.

Keywords:

Garden, older people, leisure, wellbeing, occupation, transition

Received: 1 February 2016; accepted: 26 July 2016

\section{Introduction}

Gardening is promoted as a physical work-out activity by healthy ageing literature (Hawkins et al., 2015; Park and Shoemaker, 2009; Wang and MacMillan, 2013), but leisure gardening is as much about being in the garden as it is about doing the gardening (Hawkins et al., 2013). The garden is seen as an escape; a retreat (Bhatti et al., 2009). These concepts imply that as well as being a popular leisure choice in later life (Humphrey et al., 2011), gardening also offers a range of leisure experiences. Gardening benefits people in many ways, and health and social impacts are well established (Wang and Macmillan, 2013; Wiseman and Sadlo, 2015; York and Wiseman, 2012), as is the importance of leisure occupations for people undergoing the occupational transition of retirement (Pepin and Deutscher, 2011). Research about leisure in later life tends to focus on the instrumental outcomes of health and social connection, which are considered to be protective and extend the healthy years of life (Adams

\footnotetext{
${ }^{1}$ Occupational therapist, Independent Living Service, West Sussex County Council, UK

${ }^{2}$ Senior Lecturer Occupational Therapy, University of Brighton, UK
} 
et al., 2011). However, there is evidence that suggests enjoyment in later life is associated with longer survival, even when demographic and health factors are accounted for (Steptoe and Wardle, 2012). The National Gardens Scheme has been supporting individuals in the United Kingdom (UK) to open their private gardens to the public since the 1920s, and they estimate these gardens attract around 750,000 visitors every year (NGS, 2013). Although there is an active and committed garden visiting community, there is currently no empirical research about the experience of garden visiting. This lack of evidence may be because research has tended to focus on gardening as a creative and embodied physical act, rather than the experience of simply being in and appreciating the garden. For many people, being in the garden is as important as the act of gardening (Hawkins et al., 2013). Therefore, the aim of this study is to explore the experiences of people in later life who visit gardens for leisure, in order to untangle the being from the doing, and perhaps begin to challenge the focus on the activity in active ageing, and re-value the importance of enjoyment.

\section{Literature review}

The ageing population is discussed as a problem in some literature, which results in a problematised view of later life driving the research agenda (Department of Health, 2001). Later life is also viewed as a time for growth, personal development and pleasure (DEMOS, 2014). Retirement has been theorised as the 'third age', a rewarding stage of life with increased opportunities for leisure that reflects this second view (Roberts, 2006). These two views of later life appear to be conflicting. This contradiction is because the 'ageing population' and 'demographic boom' discussions are often about disability and the need for care in later life, whilst the 'time for growth and personal development' view focuses on retired and well resourced 'active agers' (Wiggins et al., 2004). The current research focuses on the space in the middle of these contrasts, where people can enjoy leisure that is carried out at a more relaxed pace.

Wilcock (2006) has explored the core belief within occupational science that there is a strong, symbiotic link between occupation and wellbeing. Leisure, productivity and self-care are widely considered to be the three key areas of occupation, with leisure being defined as occupations done for pleasure (Sumsion et al., 2012). This definition is pragmatic, but misses an opportunity to explore the complex nature of occupation. Fallahpour et al. (2015) have questioned whether we effectively engage with the concept of leisure within occupational therapy, and whether we are able to fully comprehend leisure by applying our current, activity based definitions. A systematic review by Adams et al. (2011) further highlights the need for more emphasis on the meaning and purpose of leisure as perceived by the individual.

Walking is an example of a gentle leisure occupation which can increase perceptions of wellbeing and create a feeling of connection to nature (Wensley and Slade, 2012). Gardens in particular are spaces with implications for wellbeing, and Kaplan's seminal publication on attention restoration theory suggests that natural environments can have restorative effects and reduce stress by engrossing people in the natural world (Kaplan, 1995). Natural environments have also been found to increase people's vitality and wellbeing (Cosgriff et al., 2010; Ryan et al., 2010), and horticultural activities have been found to have a positive affect in mental health recovery (Kam and Siu, 2010). Research focusing on the domestic garden has found that people value their role as a gardener greatly and feel a deep spiritual attachment to their garden, especially if they are facing a serious illness (Unruh and Hutchinson, 2011). Freeman et al. (2012) furthered this understanding by interviewing 55 garden owners and finding that people see their gardens as a very personal space which they 
use to express themselves. The domestic garden as a personal space has further been explored by Bhatti et al. (2013), who found that people highly value privacy within their own gardens. As garden visiting often involves entering gardens which would normally be private spaces, this activity could facilitate an interesting exploration of the interplay between occupations which take place in the private domestic sphere and public, social occupations. The relationship between being in the garden and doing gardening is complex, and research has found that simply being in the garden environment holds value for individuals, alongside the actual act of gardening (Hawkins et al., 2013). Doing, being and becoming are key concepts within occupational science (Wilcock, 2006). Considering how people can become through being in the garden and doing garden visiting could contribute to our understanding of the connections between wellbeing and outdoor leisure. Furthermore, defining leisure as a broad personal experience as opposed to visible participation in a discrete activity may allow more opportunity for being and becoming to be considered as part of the occupation.

There is an increasing evidence base around the cognitive, physical, psychological and spiritual benefits of gardening for older people, as evidenced by Wang and Macmillan's systematic review (2013). A critical review of gardening as an occupation also found a strong connection between gardening and wellbeing (York and Wiseman, 2012). Both reviews focused mainly on gardening as therapy as opposed to typical, domestic gardening, suggesting that further research is needed to enhance our understanding of ordinary gardens as experienced without therapy. Garden visiting is an inclusive occupation which is not dependent on a person's physical capacity or resources. Furthermore, exploring being in the garden environment without actually doing gardening has the potential to increase our understanding of the complex relationship between the environment of the garden and the occupation of gardening.

\section{Method}

Due to the prevalence of quantitative literature on leisure for people in later life, qualitative phenomenological research has been identified as most appropriate for furthering knowledge in this area. This approach values individual meaning, and aims to describe a phenomenon through the lived experience of individuals (Creswell, 2014). The research methodology specifically comprised of a critical realist ontology and an interpretivist epistemology, which recognises that the experience of reality is subjective and socially constructed (Finlay, 2006). For the interpretivist researcher, research is often a journey of self-discovery as they are a part of the world being studied (Finlay, 2006). To account for this, reflexive thinking was engaged in throughout the research process, in the form of reflective writing and discussions. This process allowed assumptions and preconceptions to be identified, and their impact to be actively reflected upon to acknowledge their influence on the research.

\section{Participants}

Ethical approval was granted by the School of Health Sciences Research Ethics and Governance Panel at the University of Brighton. A local individual who regularly opens his garden for visitors agreed to act as the community partner for this project. This individual emailed a research invitation to his own contact list of approximately 550 people with an interest in garden visiting. Everyone who expressed interest was sent a more detailed information sheet to consider, and was made aware anonymised quotations would be used in the research write-up and that they could withdraw at any time without giving a reason. Each participant gave written consent. Six women and one man were recruited, aged between 
60 and 81 years. Every individual who expressed interest in the study was included, excluding one person who was still working and therefore did not fit the criteria. All participants were white British and had retired relatively early into reasonably stable economic situations, although the variety of marital statuses and sexualities illustrates they were not a homogenous group (Table 1). To be included in this research, participants had to consider themselves fully retired, be in good enough health to engage comfortably in a one hour interview and have previously visited gardens for leisure. Funding was not available for a translator, therefore a potential limitation of this recruitment is that only fluent English speakers were considered.

\section{Procedure}

Semi-structured interviews (Patton, 2002) were used to gather information about individuals' experiences. The interview questions were developed by the research team (Table 2). These were informed by Unruh and Hutchinson's (2011) research on gardening and spirituality because it was identified as using a similar approach and exploring ideas relevant to this research. Additional questions were asked to encourage participants to expand on interesting answers or to follow up on unexpected answers, such as 'Can you tell me a bit more about that?' and 'Why do you think that is?' Individual interviews, rather than focus groups, were used for five of the seven participants, as although garden visiting is a social activity, it is not dependent on a closed, fixed group. The other two participants were married to each other, and reported usually visiting gardens together. After reflecting on the aims of the method in supervision, these participants were interviewed together so the interview would reflect their experience of visiting gardens together. To ensure that the methods used were congruent with the aims and methodology of the project, interviews were conducted whilst walking outdoors through public gardens. This active approach to interviewing has previously been used very effectively when exploring outdoor mountain biking, as experiencing the occupation during the interview can lead to rich and honest data about the participants' relationships with nature and outdoor occupations (King and Church, 2013). For this reason a traditional indoor, sedentary interview which would have been removed from both the occupation and the environment under discussion was not chosen.

\section{Data analysis}

Interviews were transcribed verbatim and anonymised prior to being analysed using Braun and Clarke's (2006) model of thematic analysis. Inductive coding was used in order to allow the themes to arise naturally from the data (Braun and Clarke, 2006). This approach allows participants' voices to be of central importance in the analysis, in keeping with the methodology of this research. Each transcript was listened to and read multiple times, and interesting ideas were noted in the margins. Upon repeated reading these ideas were assigned codes, which were then categorised into themes and subthemes. Attention was given to disconfirming data throughout the analysis to ensure an open minded approach (Jones et al., 2014), and different interpretations were given careful consideration during the analysis stage. Third party verification was achieved through supervision and peer review. All participants were emailed a summary of the themes for member checking. 
Table 1. Participant demographic details.

\begin{tabular}{|l|l|l|l|}
\hline $\begin{array}{l}\text { Participant } \\
\text { (pseudonym) }\end{array}$ & Age & $\begin{array}{l}\text { Approximate age } \\
\text { at retirement }\end{array}$ & Marital status \\
\hline Kate & 66 & 53 & $\begin{array}{l}\text { Living with same-sex } \\
\text { partner (partner not } \\
\text { in the study) }\end{array}$ \\
\hline Melissa & 61 & 58 & $\begin{array}{l}\text { Married (husband } \\
\text { not in the study) }\end{array}$ \\
\hline Grace & 81 & 58 & $\begin{array}{l}\text { Married (husband } \\
\text { lives in care home) }\end{array}$ \\
\hline Emma & 60 & 57 & $\begin{array}{l}\text { Living with same-sex } \\
\text { partner (partner not } \\
\text { in the study) }\end{array}$ \\
\hline Philip & 69 & 63 & Married to Ann \\
\hline Ann & 65 & 59 & Married to Philip \\
\hline Sarah & 63 & 61 & Divorced \\
\hline
\end{tabular}

Table 2. Interview schedule.

1. Can you tell me about how your interest in garden visiting began?

2. Do you usually visit gardens by yourself or with someone?

3. Do you have a garden? Did you garden before you began visiting gardens?

4. Can you describe a garden you've visited that particularly stands out in your mind?

5. Do you think your interests have changed or stayed the same since you retired?

6. What qualities of garden visiting give you satisfaction?

7. Do you think garden visiting contributes to your quality of life?

\section{Findings}

All seven participants were keen gardeners as well as enthusiastic garden visitors. For most people the two occupations were interlinked, with people explicitly making links between their own garden and the gardens they visited. Philip, Ann, Grace and Melissa (pseudonyms) also opened their gardens to the public, and Kate was seriously considering it. For them, garden visiting and garden opening were two perspectives on the same occupation, as sharing their space inevitably affected their experience of visiting gardens. Sarah and Emma did not consider their garden to be 'of opening standard', although they still enjoyed sharing their gardens with friends and family. 
The main themes identified in this data were around time and wellbeing, embodied wellbeing and pondering the creator. Garden visitors are also seen as being part of an active local community of gardeners and garden visitors.

Time and wellbeing

Being present

There's an issue about living in the present isn't there, and really experiencing what you have now and outdoor spaces definitely do that, they make you really think about what's going on, you're not sitting in your own living room thinking, 'I really must do something with those curtains', or all this nonsense that goes through your head. (Emma)

The physical, emotional, social and spiritual benefits of garden visiting were explicitly discussed, with people seeing garden visiting as making an important contribution to their quality of life. Philip considered it 'very destressing' to simply live in the moment and 'watch what's happening' when visiting a garden. The idea that gardens can be an oasis in the city, a tranquil space where you can forget the day-to-day worries and simply enjoy the here and now, was prominent in these interviews.

Noticing change, noticing the moment

It's not static, it's always changing so... there's always something to notice.

(Sarah)

Visiting gardens was seen as a way of connecting with the natural world. People noted seasonal flowers such as snowdrops starting to grow and associated this with the changing seasons. Many people viewed spring flowers coming through as 'signs of hope' (Melissa). The sense that a garden is a 'living organism' (Philip) was also prominent, and this constant change provided the stimulation needed to be in touch with nature as it was at the present moment.

Embodied wellbeing

Sensory engagement

If you're going to see what's there you're going to go slowly ... all your senses

are involved. (Philip)

People enthused about the sensory delights of being in a garden. Enjoying the smells and sounds of the garden was seen as a source of simple yet profound pleasure. Aesthetic appreciation of the design and colours of the plants was also a vital part of experiencing a garden. By stopping to smell a flower, feel a leaf and listen to the buzz of an insect you are drawn into the garden and into the present moment. This sensory engagement was considered to be an end in itself when visiting gardens. 
Pondering the creator

The person behind the garden

I mean gardens, they're so different, every, everyone you go to ... you give 20

people a piece of ground and they all produce something different. (Grace)

Gardens were seen as a space which has been carefully designed and maintained by people. Everyone was curious to know about the person behind the garden, whether it was someone they knew well, had just met, or someone they were purely speculating about. Sarah saw visiting a friend's garden as 'an extension of the relationship, of the friendship . . . because it's part of her ... her creation'. Equally, people would see the garden as a reflection of its creator even if it was someone they didn't know, with Ann remembering a 'very precise lady' she once met, who had a 'very precise garden'. Sarah even spoke of peering into people's gardens when out walking, and creating stories about who owned the garden, what their lives might be like and imagining why their garden looks the way it does. Gardeners are viewed as being intimately connected to their gardens, whether they are strangers or people that are close.

The garden as a personal creation

I'm divorced, and so you know I had to move ... far away... so you feel that I say look I've done this, I've sorted this, I'm, I'm okay, I'm, you know, creating something here. (Sarah)

Designing and sharing a garden with visitors was seen as a way of sharing a life with others. Even the participants who didn't formally open their gardens to the public took pride in entertaining friends and family in their gardens, and in sharing this private space. Emma spoke about the pleasure of seeing 'things that I've cultivated coming up', a sense of pride that was echoed by all participants. Melissa felt a 'buzz having all the lovely comments' when she opened her garden, and gained great satisfaction from knowing that the garden she had carefully cultivated was giving other people ideas and inspiration. Gardening was seen as personal expression, with their garden being connected to their identity.

\section{Being part of a gardening community}

Sharing

... a more broad, humanity aspect to that, where you're just ... you know, even if you don't really know the person very well you're willing to give them a plant. .

. or they'll give you one. (Kate)

Gleaning ideas for your own garden was a prominent idea in this research, an idea embodied by the physical sharing of seeds and cuttings between gardeners. Having someone else's plant growing in your garden symbolised the interconnectedness of this community, with Emma describing the joy of 'watching things come up and realising where l'd got them from, that they'd actually come from people'. 
Gardeners use garden visiting to learn about different plants and how to grow them, and often relish the opportunity to chase a rare plant after seeing it in a garden. Garden visiting came across as a reciprocal relationship, with most people being as interested in being able to share something with others as they were in gaining ideas for themselves.

\section{Social connections}

It's an ever widening circle. (Grace)

Meeting like-minded people is an important aspect of being part of a local community of garden visitors. For some participants, the community was viewed very loosely; stopping to have a conversation with a stranger in a garden. For others, such as Grace, the sense of community was tighter knit, with many of her friends and family members also being keen gardeners and garden visitors. Social rituals such as enjoying tea and cake during a garden visit appeared to be an integral part of the overall experience, illustrating the important social element to this occupation.

Committing to your community

It's quite a commitment. (Melissa)

Some participants spoke of wanting to open their own gardens just so they could more fully participate in the garden visiting community, by making the commitment to share their own garden as well as visit other people's gardens. The overall impression from the data was that making a commitment to the garden visiting community made the overall leisure experience richer and more meaningful, instead of making the gardening hard work. Indeed, part of Kate's motivation to want to open her garden was so she could 'offer the same that I, we receive from others when we go visit gardens ... that same gift that you get, which is sort of, is a generous ... warmth', illustrating the complex benefits committed leisure can bring to both an individual and a community.

The private garden as a microcosm of the public garden

It opened up a whole new way of thinking about her personal space and, you know, it being good enough and big enough to, to open up to the public. (Emma)

Different experiences of garden visiting were evident in these interviews, with some people focusing more on visiting large public gardens and some people homing in on small private gardens. Emma spoke about parks, and the important role public, outdoor spaces have played in her having a sense of community throughout her life. Similarly, individuals opening their private gardens for the public are providing a space for communities of people, a space which is personalised as you know exactly who designs it and maintains it. Philip and Ann initially felt sceptical about people wanting to visit their small garden, until they began visiting local gardens and realised that 'people were interested in just the very ordinariness of it and I thought "well, yes, we can do that"' (Ann). 
These four themes of time and wellbeing, embodied wellbeing, being part of a gardening community and pondering the creator are themes which resonate within the existing body of knowledge of gardening and garden environments. The importance of gardens as a space for engaging all the senses, reducing stress and living in the present moment provides further support for attention restoration theory (Kaplan, 1995). The therapeutic value of being connected to nature also supports the connections between nature and wellbeing explored by Ryan et al. (2010) and Cosgriff et al. (2010). Evidence for the connection between gardening and wellbeing as described by York and Wiseman (2012), Wang and Macmillan (2013) and Wiseman and Sadlo (2015) is also found in this current research. Reflexivity and supervision discussions revealed a potential bias in that both researchers are occupational therapists and believe strongly in a connection between occupation and wellbeing. This potential bias was regularly discussed in supervision meetings and also addressed in reflexive writing to minimise the impact on this research.

In these interviews, these garden visitors can be viewed as a subset of gardeners who explicitly value the inspiration and stimulation of visiting other gardens. It has previously been found that people value privacy above all else in their gardens (Bhatti et al., 2013). However, this research has revealed a contrasting approach to private space by focusing on the gardens which move between the public and private spheres, and the gardeners who actively incorporate ideas from other gardens into their own. The sharing of plants and ideas permanently connects a garden to other people, whether loved ones or strangers, through the associations created by planting someone else's cutting in a private garden.

The idea that the private garden can function as a microcosm of the public garden suggests these research findings may have implications for how we understand the significance of larger public gardens as well as the private domestic garden. The benefits garden visiting can provide in terms of temporal and sensory engagement are likely to be transferable to similar garden situations, both nationally and internationally. The National Trust and the Royal Horticultural Society both encourage the sharing and appreciation of gardens and natural environments within the UK. The sense of local community evoked through gardens could be considered in relation to public gardens and outdoor spaces as well as to the private domestic garden.

Internationally, there is a multitude of comparable garden-based organisations who could also benefit from this deepened understanding of the benefits of garden visiting, such as The Garden Conservancy in the United States of America, the Swedish Horticultural Society and the New Zealand Gardens Trust. The therapeutic benefits of gardens is a theme evident in international publications (Cosgriff et al., 2010; Kam and Siu, 2010; Unruh and Hutchinson, 2011; Wiseman and Sadlo, 2015). Indeed, the themes in this research around wellbeing, community and pondering the creator can be seen to represent universal human needs, which may well be manifested in outdoor spaces around the world.

The meaning which is created through garden visiting, on both an individual and community level, can be further understood in relation to the occupational science concept of becoming (Wilcock, 2006). Garden visitors are not only doing gardening and being in various gardens, but becoming part of an extended meta-garden, sustained by the sharing of plants and ideas within the garden visiting community, and thus finding a sense of belonging. 
Previous research has found connectedness, spirituality and meaning to be important themes in relation to the garden (Freeman et al., 2012; Unruh and Hutchinson, 2011). Whereas Unruh and Hutchinson (2011) explicitly focused on 'spiritually' in the context of palliative participants, research focusing on people in typical health has also found that gardens can create a profound feeling of being connected with people and with nature (Freeman et al., 2012). This sense of interconnectedness is echoed in this research, suggesting the private garden has important implications for meaning and belonging. Many people are attracted to the ordinary, rather than the grand, wanting to see familiar urban gardens they can compare with their own. The joy and wellbeing people associated with this everyday environment suggests gardens can be a space for finding the divine in the quotidian, an idea which relates to and expands upon the findings of Freeman et al. (2012) and Bhatti et al. (2013) regarding the profound spiritual meaning people create in everyday occupations and landscapes. Indeed, garden visiting can be argued to add a social dimension to the meaningful occupation of private gardening, which allows the benefits of a perhaps solitary occupation to be enhanced and shared within a community.

All the participants in this study saw gardening as a leisure occupation, despite the high levels of commitment and responsibly the individuals felt towards their gardens and garden-based communities. This perhaps contradicts the pragmatic definition of leisure as a contrast to productivity and self-care, which is frequently used in occupational therapy (Sumsion et al., 2012). The individuals in this study experienced garden visiting as being deeply connected with the occupation of gardening, and whether they shared their gardens with the public or only with loved ones, having people visit their garden affected their experience of visiting other gardens. Embracing the subjectivity of experience allows for this perceived connection between occupations to be embraced as part of the overall experience of leisure, and complicates the initial approach to 'garden visiting' as a discrete leisure activity that can be studied. As stated by Fallahpour et al. (2015) and Adams et al. (2011), leisure is a complex concept which cannot be understood through a narrow focus. Therefore, the researchers strove to be aware of the current limits of understanding around leisure occupations and leisure experiences throughout this research.

The people in this study all retired with the economic means to engage in meaningful leisure occupations, suggesting they are living in the 'third age' as defined by Roberts (2006). The UK has an ageing population, and helping people remain socially connected and active in later life is a current health and wellbeing priority from the Department for Work and Pensions (DWP, 2014) and the National Institute for Health and Clinical Excellence (2008). Retirement policy is currently in transition in the UK, which has led to anxieties about the rising age of eligibility for a state pension (DWP, 2014). Participants were keen to emphasise both gardening and garden visiting as cheap occupations which were accessible for everyone. Regarding this angle, the researchers engaged in reflexive thinking about the complex relationship between the researcher and the participant in supervision sessions, to try to further understand the participants within their own culture. Most of the participants were able to retire in their fifties with access to the resources they needed to enjoy a comfortable retirement, and they would all have been aware of the changing retirement policies. The lead researcher was a student in her twenties at the time of the interviews, and it is possible this dynamic affected how the participants wished to portray themselves. This research is irremovable from its socio-political climate, and it can be argued that the ongoing policy changes around retirement are surrounded by a sense that the third age may cease to exist if the age of eligibility for a state pension continues to rise. These findings are a snapshot of 
experience which has been co-constructed by the participants and the researchers at a specific moment in history. It is possible the occupation

of garden visiting may be completely different in a different

epoch, with a different retirement culture.

\section{Limitations and recommendations for further research}

The issue of transferability is complex here, as although all the participants come from a similar socioeconomic background, it is likely this is an accurate representation of the demographic which forms the garden visiting community. Six of the seven participants were female, so it would have been interesting to have a better balance of genders as both genders engage in this occupation. Due to the time scale limitations of the project, all interviews took place in February, when the official garden visiting season is closed. These findings suggest the experience of garden visiting is different during different seasons, meaning further research could involve multiple interviews throughout the year, following the research model of Unruh and Hutchinson (2011). Additionally, research focusing on the experience of garden opening would make a useful addition to this body of knowledge by further teasing apart the occupations of garden visiting, gardening and garden opening.

\section{Implications for practice}

It is useful to recognise the importance of the domestic garden as a leisure site. Garden visiting allows many people to experience a sense of purpose and belonging, through feeling connected to nature and being part of a community. This study has deepened our understanding of the profound importance the domestic garden can have for individuals, an idea which should be acknowledged and actively engaged with during occupational therapy practice. This may be particularly significant when considering the importance of supporting people with disabilities to access gardens and outdoor spaces, both their own private gardens and larger public open spaces.

Further research is needed to expand upon the ideas explored in this research, particularly around how leisure activities are perceived and conceptualised in an occupational therapy context, the relationship between private and public gardens, and the complex relationship between garden visiting, garden opening and gardening.

\section{Conclusion}

This study has deepened our understanding of garden visiting as a complex occupation which can enhance the wellbeing of both individuals and communities through the holistic benefits it brings. Furthermore, bringing the private domestic garden into the public domain through garden visiting challenges the way we conceptualise public and private space through the medium of the garden. Considering the complex benefits gardens can provide through experiences of wellbeing allows the domestic garden to be appreciated as an everyday space with profound significance.

\section{Key findings}

- Garden visiting is an occupation with clear implications for community and individual wellbeing. 
- Garden visiting creates a meaningful sense of being connected to nature and to a community of gardeners.

\section{What the study has added}

This research has deepened our understanding of the benefits of garden visiting for people in later life. This study also furthers our knowledge around the benefits garden environments can bring to local communities.

\section{Acknowledgements}

This research was carried out as part of an MSc. Sincere thanks to Geoff Stonebanks, Charity Fundraiser through Driftwood Open Garden Seaford (www.driftwoodbysea.co.uk) and an active member of the garden visiting community, for his valuable assistance with participant recruitment.

Research ethics

Ethical approval was given by the School of Health Sciences Research Ethics and Governance Panel at the University of

Brighton, 6 November 2013.

Declaration of conflicting interests

The authors confirm that there is no conflict of interest

\section{Funding}

This research received no specific grant from any funding agency in the public, commercial, or not-for-profit sectors.

To Cite this Paper:

Leaver R, Wiseman T (2016) Garden visiting as a meaningful occupation for people in later life. British Journal of Occupational Therapy. 79(12) 768-775

\section{References}

Adams KB, Leibbrandt S and Moon H (2011) A critical review of the literature on social and leisure activity and wellbeing in later life. Ageing and Society 31(4): 683-712.

Bhatti M, Church A, Claremont A, et al. (2009) 'I love being in the garden': Enchanting encounters in everyday life. Social \& Cultural Geography 10(1): 61-76.

Bhatti M, Church A and Claremont A (2013) Peaceful, pleasant and private: The British domestic garden as an ordinary landscape. Landscape Research 39(1): 40-52.

Braun V and Clarke V (2006) Using thematic analysis in psychology. Qualitative Research in Psychology 3(2): 77-101.

Cosgriff M, Little DE and Wilson E (2010) The nature of nature: How New Zealand women in middle to later life experience nature based leisure. Leisure Sciences 32(1): 15-32.

Creswell JW (2014) Research Design: Qualitative, Quantitative and Mixed Methods Approaches, 4th edition, international student edition. Thousand Oaks, CA: SAGE.

DEMOS (2014) 'A Vision for Care Fit for the Twenty-First Century. . .'. London: HMSO. 
Department of Health (2001) National Service Framework for Older People. London: HMSO.

Department for Work and Pensions (2014) Fuller Working Lives - A Framework for Action. London: DWP. Available at:

https://www.gov.uk/government/uploads/system/uploads/attachment data/file/319872/f uller-working-lives.pdf (accessed 6 August 2014).

Fallahpour M, Borell L, Luborsky M, et al. (2015) Leisure-activity participation to prevent later life cognitive decline: a systematic review. Scandinavian Journal of Occupational Therapy 23(3): 162197.

Finlay L (2006) Mapping methodology. In: Finlay L and Ballinger C (eds) Qualitative Research for Allied Health Professionals: Challenging Choices. Chichester: John Wiley \& Sons, 9-29.

Freeman C, Dickinson KJM, Porter S, et al. (2012) 'My garden is an expression of me': Exploring householders' relationships with their gardens. Journal of Environmental Psychology 32(2): 135-143.

Hawkins JL, Mercer J, Thirlaway KJ, et al. (2013) 'Doing' gardening and 'being' at the allotment site: Exploring the benefits of allotment gardening for stress reduction and healthy ageing. Ecopsychology 5(2): 110-125.

Hawkins JL, Smith A, Backx K, et al. (2015) Exercise intensities of gardening tasks within older adult allotment gardeners in Wales. Journal of Aging and Physical Activity 23(2): 161-168.

Humphrey A, Lee L and Green R (2011) Aspirations for later life: A report of research carried out by the National Centre

for Social Research on behalf of the Department for Work and Pensions (Research Report No 737). Available at: http://dera.ioe.ac.uk/3563/1/rrep737.pdf (accessed 7 July 2014).

Jones SR, Torres V and Arminio J (2014) Negotiating the Complexities of Qualitative Research in Higher Education: Fundamental Elements and Issues, 2nd ed. New York: Routledge.

Kam MCY and Siu AMH (2010) Evaluation of a horticultural activity programme for persons with psychiatric illness. Hong Kong Journal of Occupational Therapy 20(2): 80-86.

Kaplan S (1995) The restorative benefits of nature: Toward an integrative framework. Journal of Environmental Psychology 15(3): 169-182.

King K and Church A (2013) 'We don't enjoy nature like that': Youth identity and lifestyle in the countryside. Journal of Rural Studies 31(2013): 67-76.

National Gardens Scheme. NGS: Gardens open for Charity. Available at: http://www.ngs.org.uk (accessed 17 July 2013).

National Institute for Health and Clinical Excellence (2008) Occupational Therapy Interventions and Physical Activity Interventions to Promote the Mental Well-Being of Older People in Primary and Residential Care. NICE Public Health Guidance 16. London: NICE. Available at: http://www.nice.org.uk/nicemedia/live/11999/42395/42395.pdf (accessed 11 July 2013).

Park S and Shoemaker C (2009) Observing Body Position of Older Adults While Gardening for Health Benefits and Risks. Activities, Adaptation \& Aging 33(1): 31-38.

Patton MQ (2002) Qualitative Research and Evaluation Methods. London: SAGE. 
Pepin G and Deutscher B (2011) The lived experience of Australian retirees: 'I'm retired, what do I do now?' British Journal of Occupational Therapy 74(9): 419-426.

Roberts K (2006) Leisure in Contemporary Society, 2nd ed. Wallingford: CABI.

Ryan RM, Weinstein N, Bernstein J, et al. (2010) Vitalizing effects of being outdoors and in nature. Journal of Environmental Psychology 30(2): 159-168.

Steptoe A and Wardle J (2012) Enjoying life and living longer. Archive of International Medicine 172(3): 273-275.

Sumsion T, Tischler-Draper L and Heinicke S (2012) Applying the Canadian model of occupational performance. In: Duncan EAS (ed.) Foundations for Practice in Occupational Therapy, 5th ed.

Edinburgh: Churchill Livingstone, 81-91.

Unruh A and Hutchinson S (2011) Embedded spirituality: Gardening in daily life and stressful life experiences. Scandinavian Journal of Caring Sciences 25(3): 567-574.

Wang D and Macmillan T (2013) The benefits of gardening for older adults: A systematic review of the literature. Activities, Adaption \& Aging 37(2): 153-181.

Wensley R and Slade A (2012) Walking as a meaningful leisure occupation: The implications for occupational therapy. British Journal of Occupational Therapy 75(2): 85-92.

Wiggins RD, Higgs PFD, Hyde M, et al. (2004) Quality of life in the third age: Key predictors of the CASP-19 measure. Ageing and Society 24(5): 693-708. Wilcock A (2006) An Occupational Perspective of Health, 2nd ed. Thorofare, NJ: SLACK Incorporated.

Wiseman T and Sadlo G (2015) Gardening: An occupation for recovery and wellness. In: Soderback I (ed.) International Handbook of Occupational Therapy Interventions. Switzerland: Springer International Publishing, 797-809.

York M and Wiseman T (2012) Gardening as an occupation: A critical review. British Journal of Occupational Therapy 75(2):76-84. 